\title{
PERDAS POR EROSÃO E RENDIMENTOS DE SOJ A E DE TRIGO EM DIFERENTES SISTEMAS DE PREPARO DE UM LATOSSOLO ROXO DE DOURADOS (MS) ${ }^{(\mathbf{1})}$
}

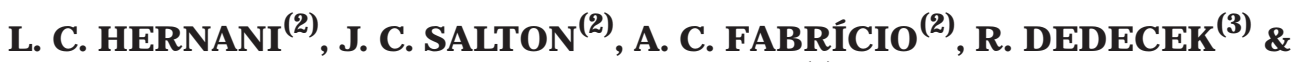 \\ M. ALVES J ÚNIOR ${ }^{(4)}$
}

\begin{abstract}
RESUMO
Avaliaram-se as perdas de solo e de água por erosão, em um latossolo roxo muito argiloso, com $0,03 \mathrm{~m} \mathrm{~m}^{-1}$ de declividade, da área experimental da E mbrapaCentro de Pesquisa Agropecuária do Oeste, em Dourados (MS), entre junho de 1987 e maio de 1995. Os tratamentos, aplicados antes da semeadura de trigo e de soja, cultivados em sucessão, foram: (i) escarificação + gradagem niveladora (ES), (ii) gradagens pesada + niveladora (GP), (iii) plantio direto (PD) e (iv) aração com arado de discos + duas gradagens niveladoras, sem cobertura vegetal (DE). 0 preparo de solo e a semeadura foram realizados no sentido do declive. O PD foi o tratamento mais eficiente, tanto no controle de perdas de solo e de água quanto em rendimentos de grãos de soja e de trigo. As perdas médias de solo e de água por erosão, relativas aos sistemas PD, ES, GP e DE, foram, respectivamente, de: 0,$8 ; 2,8 ; 5,3$ e 7,3 t ha-1 ano-1 $^{-1}$ $27,80,112$ e $149 \mathrm{~mm}$ ano $^{-1}$. O PD, quando comparado ao DE, controlou $89 \%$ das perdas de solo e $82 \%$ das de água. O PD mostrou rendimentos médios de grãos, tanto de soja como de trigo, $17 \%$ superiores aos do GP. O ES apresentou rendimentos médios $5 \%$ superiores em soja e $12 \%$ superiores em trigo, quando comparados aos do GP. Este último, dos tratamentos cultivados, foi o menos eficaz, seja no controle à erosão, seja nos rendimentos de soja e trigo. $\mathbf{O}$ fator erosividade, $\mathbf{R}$, foi estimado em 6.411 MJ mm ha-1 $\mathrm{h}^{-1}$ ano-1, e a erodibilidade, $K$, foi de $0,0045 \mathrm{t} \mathrm{h} \mathrm{MJ}^{-1} \mathrm{~mm}^{-1}$. Entre junho/94 e mai o/95, o período de maior intensidade de perdas por erosão por unidade de tempo foi do preparo de solo à semeadura da soja, e o de maiores perdas absolutas foi o de 30 a 60 dias após a semeadura dessa cultura. Isso demonstra a importância de adequada cobertura do solo, entre novembro e março, e reforça a recomendação do Sistema de Plantio Direto para a região de Dourados (MS).
\end{abstract}

Termos de indexação: plantio direto, escarificação, gradagem, erosividade, erodibilidade.

\footnotetext{
(1) Recebido para publicação em maio de 1996 e aprovado em outubro de 1997.

(2) Pesquisador da EMBRAPA-Centro de Pesquisa Agropecuária do Oeste, Caixa Postal 661, 79804-970 Dourados (MS).

(3) Pesquisador da EMBRAPA-Centro Nacional de Pesquisa de Florestas, Caixa Postal 319, 83411-000 Colombo (PR).

(4) Assistente de Pesquisa da EMBRAPA-CPAO, Caixa Postal 661, 79804-970 Dourados (MS).
} 


\title{
SUMMARY: EROSION LOSSES, SOYBEAN AND WHEAT YIELDS UNDER DIFFERENT TILLAGE SYSTEMS ON AN EUTRORTHOX SOIL AT DOURADOS (MS).
}

\begin{abstract}
Soil and water losses wereeval uated from 1987 to 1995, on a very clayey red dusky latosol, with $0.03 \mathrm{~m} \mathrm{~m}^{-1}$ slope, of E mbrapa-Centro de Pesquisa Agropecuária do Oeste, at Dourados, Mato Grosso do Sul State, Brazil. Soil tillage systems used for growing wheat and soybean in successi on were: chisel pl ow +tandem disk (ES), offset disk +tandem disk (GP), no tillage(PD) and conventional tillage, with no vegetable cover (DE). All tillage operations and seeding were in theup and down hill. PD was themost efficient tillagesystem to control soil and water losses and was the most productive GP was the least efficient. Means of soil and water losses for PD, ES, GP and DE were, respectively: $0.8 ; 2.8 ; 5.3$ and 7.3 t ha $^{-1}$ year ${ }^{-1}$, and $27,80,112$, and 149 mm year-1. Compared to DE, thePD controll ed $89 \%$ of soil and $82 \%$ of water erosion losses, and yiel ded $17 \%$ moresoybean and wheat grain than GP. As for wheat, ES was $12 \%$ moreproductive than GP. Rainfall-run off erosivity factor (R) was $6.411 \mathrm{MJ} \mathrm{mm} \mathrm{ha-1}^{-1} \mathrm{~h}^{-1}$ year-1, and theerodibility fator $(\mathrm{K})$ was $0.0045 \mathrm{t} \mathrm{h} \mathrm{MJ}^{-1} \mathrm{~mm}^{-1}$, reflecting characteristics of high infiltration and high internal drainage of this soil. During the 1994/ 95 growing season, the highest soil loss period per timeunit was from seedbed preparation to seeding soybean, and theperiod of highest absolute soil erosi on l osses was from 30 to 60 days after seeding soybean. Thi s shows thegreat i mportance of soil cover, specially during the inicial cropping phase, and support the recommendation of the no tillagesystem for this region.
\end{abstract}

Index terms: no tillage, chisel plow, rain-runoff erosivity, soil erodibility.

\section{INTRODUÇÃO}

A sustentabilidadedos agrossistemas édiretamente influenciada pela forma de manejo dos solos e das culturas. No Mato Grosso do Sul (MS), olatossol oroxo muito argil oso (LR) ocorre em cerca de 3,8 mil hões de hectares, sendo, na maioria, álico, pobre em cálcio, magnésio e fósforo (Mato Grosso do Sul, 1990). Nesse Estado, predominam a pastagem extensiva e o monocultivo de soja. O sistema de preparo de solo, usado em cerca de $70 \%$ da área cultivada, envolve gradagens pesadas enivel adoras, em número excessivo de operações anuais, produzindo desagregação e encrostamento superficiais do solo, compactação subsuperficial e incrementos em perdas por erosão.

Os latossolos sofrem intenso processo erosivo, quando submetidos a sistemas de preparo e cultivos impróprios (Dedecek \& Cabeda, 1977). Resultados de pesquisa sobre efeitos de sistemas de manejo de solo em perdas por erosão, em Mato Grosso do Sul, são bastante escassos. Fabrício (1985), num estudo realizado por dois anos em um LR com 0,03 m m-1 de declividade, de Dourados (MS), verificou que a semeadura sem preparo na sucessão trigo/soja proporcionou controle de perdas de solo e de água, respectivamente, de $95 \%$ e $93 \%$, comparada à do sistema convencional (uma aração + duas gradagens niveladoras), sem cobertura vegetal. Sob as mesmas condições edafoclimáticas, Hernani (1991) relatou que o sistema degradagens pesada +niveladora, aplicado, continuamente, no cultivo da sucessão trigo/soja, proporcionou perdas médias de solo de cerca de $6,2 \mathrm{t}^{-1} \mathrm{ano}^{-1}$, seis vezes maiores que as do sistema sem preparo. Além disso, o controle das perdas de sol o do tratamento sem preparo, em relação ao sistema convencional sem cobertura vegetal, foi de $85 \%$, tendo este último proporcionado perdas médias de solo de
7 t ha-1 ano-1. A tolerância máxima de perdas de solo para um LR de Campinas (SP) foi de $12 \mathrm{t} \mathrm{ha}^{-1}$ ano-1, $^{-1}$ segundo Lombardi Neto \& Bertoni (1975). Nessas mesmas condições edafoclimáticas, considerando o sistema convencional sem cobertura vegetal, o plantio direto reduziu em $63 \%$ as perdas de solo e em $33 \%$ as perdas deágua (Lombardi Neto et al., 1980), enquanto a escarificação reduziu em mais de $60 \%$ as perdas por erosão de um podzólico vermel ho-amarel o (Castro et al., 1982). Tal redução, entretanto, foi menor (33\%), no caso de um $L R$, em virtude da maior resistência desse solo à erosão (Castro et al., 1982 e 1986). Além disso, no LR, a escarificação não foi tão eficiente, a produtividade foi menor eas perdas de solo atingiram 2,0 t ha-1 ano $^{-1}$ (Castroet al., 1982). Em Londrina (PR), verificou-se, num LR distrófico, que a produtividade da soja foi $33 \%$ mais el evada no plantio direto e $10 \%$ maior na escarificação, quando comparada à do sistema convencional (Sidiras et al., 1983). Esses autores demonstraram que o teor e a disponibilidade de água no solo determinaram as diferenças na produtividade.

A cobertura do solo tem grande influência nas perdas por erosão, conforme demonstraram Wünsche \& Denardin (1978). Num latossolo vermel ho-escuro textura argilosa, Biscaia (1978) verificou que a cobertura sozinha reduziu as perdas de solo em $87 \%$, as quais foram de 35,$5 ; 4,6$ e 0,6 t ha-1 $^{-1}$ ano-1, respectivamente, para sistema convencional sem cobertura vegetal; convencional cultivado e plantio direto. Eltz et al. (1977) observaram que a cultura da soja, por apresentar maior cobertura de solo, foi mais eficiente em controlar a erosão do que a cultura do trigo. Dedecek et al. (1986) relataram que a soja foi mais eficiente no control e da erosão do que o mi lho ou o arroz, sendo esses efeitos ainda mais evidenciados em plantio direto. 
A erosão também pode ser estimada por meio de model os como a E quação Universal de Perdas de Solo (EUPS), de Wischmeier \& Smith (1978). Para isso, é necessária a determinação de val ores dos fatores que compõem essa equação. No Mato Grosso do Sul, trabal hos nesse sentido são raros: citam-se o de Mato Grosso do Sul (1992) que definiu linhas isoerodentes para esseEstado, e o deVitorino\& RosaJ únior (1994) que determinou o fator $\mathrm{R}$ para a região de Dourados (MS). Para o cál cul o da erosividade, ambos utilizaram o model o sugerido por Lombardi Neto \& Moldenhauer (1980), mas tomaram períodos de retorno relativamente muito estreitos, ou seja, nove anos (Mato Grosso do Sul, 1992) e onze anos (Vitorino \& Rosa J únior, 1994). O potencial erosivo das chuvas tem sido avaliado em várias outras regiões do País, citando-se os trabal hos de Rufino et al. (1993), no Estado do Paraná, e Carvalho et al. (1989), no município de Mococa (SP). Em Mato Grosso do Sul, resultados de pesquisa sobre a erodibilidade são inexistentes. Em Campinas (SP), o fator $\mathrm{K}$ foi estimado em 0,0101 t h MJ -1 mm-1, para um LR (Carvalho et al., 1993). Denardim (1990), estudando 31 solos brasileiros submetidos a experimentos com chuva natural e simulada, verificou que os latossolos apresentaram valores de erodibilidade entre 0,002 e $0,034 \mathrm{t} \mathrm{h} \mathrm{MJ}^{-1} \mathrm{~mm}^{-1}$. Os baixos val ores relativos para a erodi bi lidade dos latossol os podem estar relacionados com sua mineralogia, conforme discorreram Silva et al. (1994).

Assim, este trabalho teve por objetivo avaliar, durante o período 1987-1995, os efeitos de sistemas de preparo de um LR muito argil loso não só em perdas de solo eágua por erosão, mas também em produtividade de soja e de trigo cultivados em sucessão. Determinaram-se, também, a erosividade da chuva (fator $R$ da EUPS) e a erodibilidade (fator K) para esse solo, localizado no município de Dourados (MS).

\section{MATERIAL E MÉTODOS}

Este experimento vem sendo desenvolvido desde outubro de 1987, no Centro de Pesquisa Agropecuária do Oeste (CPAO), Iocalizado no município de Dourados (MS). Os resultados aqui analisados referem-se ao período outubro/1987 a abril/95. A região apresenta relevo plano a suave ondulado, predominância de basaltitos da Formação Serra Geral e clima Aw (Köepen), com temperatura média superior a $18^{\circ} \mathrm{C}$ e estação seca bem definida, quando a pluviosidade média mensal é inferior a $60 \mathrm{~mm}$.

Utilizou-se um latossolo roxo álico epieutrófico $\mathrm{A}$ moderado textura muito argilosa, de declividade média $0,03 \mathrm{~m} \mathrm{~m}^{-1}$, cujos atributos estão nos quadros 1 e2. Visando homogeneizar o terreno, antes do início do experimento, o solo foi corrigido quanto à acidez, fósforo, potássio e micronutrientes, correção essa baseada em análise química e recomendações de Silva et al . (1986), Souza (1987) eE MBRAPA (1991 e 1992).

Utilizaram-se parcelas permanentes de 22,0 × 3,5 m, delimitadas com chapas galvanizadas e conectadas a um sistema coletor de enxurrada, baseado em Bertoni \& Lombardi Neto (1985). Essas parcelas foram submetidas aos sistemas de preparo de solo, antes da semeadura da soja (Glycine max Merril) e do trigo (Triticum aestivum L.), cultivados em sucessão. Os tratamentos foram: (i) escarificação com escarificador de cinco hastes, distanciadas em $25 \mathrm{~cm}$ entre si, com ponteiras estreitas; trabal hando à profundidade de $25 \mathrm{~cm}$, seguida de gradagem niveladora com grade de 42 discos de $48,3 \mathrm{~cm}$ de diâmetro e profundidade de trabalho de $5 \mathrm{~cm}$ (ES); (ii) gradagem com grade pesada de 16 discos de $61 \mathrm{~cm}$ de diâmetro e à profundidade de $15 \mathrm{~cm}$, seguida de gradagem nivel adora, semel hanteà anterior (GP); (iii) plantio direto ou semeadura direta em solo coberto com palha de soja e de trigo (PD) e (iv) aração com arado de discos (três discos de $81,1 \mathrm{~cm}$ de diâmetro), à profundidade de $20 \mathrm{~cm}$, seguida de duas gradagens niveladoras (idem à anterior), com solo manual e superficialmente escarificado e mantido limpo de cobertura vegetal (DE). Todas as operações foram mecanizadas e realizadas no sentido do declive. As práticas culturais segui ram recomendações relatadas em Silva et al. (1986), Souza (1987) eE MBRAPA (1991 e 1992).

Avaliações de perdas de sol o e de água, entre 1987 e 1994, foram baseadas em Cogo (1978). Entre abril de 1994 e abril de 1995, determinaram-se as perdas de solo e de água e a percentagem de infiltração para os períodos de cultivo, conformeWischmeier \& Smith (1978), a saber: T1 - da semeadura do trigo ao $30^{\circ}$ dia; T2 - do $30^{\circ}$ ao $60^{\circ}$ dia; T3 - do $60^{\circ}$ dia após a semeadura à colheita do trigo; F1 - da colheita do trigo até o preparo de solo para a soja; S1 - do preparo à semeadura da soja; S2 - da semeadura da soja até o $30^{\circ}$ dia; S3- Do $30^{\circ}$ até $60^{\circ}$ dia; S4 - do $60^{\circ}$ dia à col heita da soja; F 2 - da col heita da soja até o preparo de solo/ semeadura do trigo subseqüente. Entre o preparo do solo e a imediata semeadura do trigo, não houve ocorrência de evento erosivo.

Para estimar a erosividade da chuva (fator R) em Dourados (MS), tomaram-se, de estação meteorológica local izada a cerca de $300 \mathrm{~m}$ do experimento, dados de chuva relativos a um período de 23 anos (1972-1994). Também foi utilizada a equação: $\mathrm{EI}=67,355(\mathrm{r} 2 / \mathrm{P}) 0,85$, baseada em Lombardi Neto \& Moldenhauer (1980); em que $\mathrm{EI}=$ média mensal do índice de erosão (MJ $\left.\mathrm{mm} \mathrm{ha}^{-1} \mathrm{~h}^{-1}\right) ; \mathrm{r}=$ precipitação média mensal $(\mathrm{mm})$ e $\mathrm{P}=$ precipitação média anual $(\mathrm{mm})$. $\mathrm{O}$ fator erodibilidade do solo (K) foi determinado, conforme Wischmeier \& Smith (1978), com vistas em corrigir a declividade $\left(0,03 \mathrm{~m} \mathrm{~m}^{-1}\right)$ para a declividade-padrão $\left(0,09 \mathrm{~m} \mathrm{~m}^{-1}\right)$, usando-se as perdas de solo obtidas no tratamento DE. O cál cul o do fator de correção do grau de declive (S) foi embasado em Wischmeier $\&$ Smith (1978), e os demais fatores foram considerados iguais a um.

Na fasefinal dematuração das culturas, obtiveramse orendimento de grãos ea matéria seca da palha, em três subamostras de 1 m². Para a análise de variância dos dados, considerou-se um delineamento de blocos ao acaso, tomando-se os anos agrícolas como repetições. As médias foram comparadas pelo teste 
Quadro 1. Valores de pH em $\mathrm{H}_{2} \mathrm{O}$, cátions trocáveis (Al, Ca, Mg, K), fósforo (P) e matéria orgânica (MO), determinados antes da instalação dos experimentos, para quatro profundidades do latossolo roxo de Dourados (MS)

\begin{tabular}{|c|c|c|c|c|c|c|c|}
\hline \multirow{2}{*}{ Profundidade } & \multirow{2}{*}{ pH $\mathrm{H}_{2} \mathrm{O}$} & \multicolumn{4}{|c|}{ Cátions trocáveis } & \multirow{2}{*}{$\mathbf{P}$} & \multirow{2}{*}{ MO } \\
\hline & & Al & Mg & $\mathrm{Ca}$ & K & & \\
\hline $\mathrm{cm}$ & & - & $-n$ & 3 & - & $\mathrm{mg} \mathrm{dm}^{-3}$ & $\mathrm{~g} \mathrm{~kg}^{-1}$ \\
\hline $\begin{array}{r}0-10 \\
10-20 \\
30-40 \\
50-60\end{array}$ & $\begin{array}{l}5,6 \\
5,5 \\
4,9 \\
4,8\end{array}$ & $\begin{array}{l}2 \\
2 \\
6 \\
6\end{array}$ & $\begin{array}{r}52 \\
46 \\
19 \\
9\end{array}$ & $\begin{array}{r}19 \\
17 \\
7 \\
3\end{array}$ & $\begin{array}{l}4,24 \\
2,79 \\
0,84 \\
0,54\end{array}$ & $\begin{array}{r}118 \\
67 \\
19 \\
15\end{array}$ & $\begin{array}{l}28 \\
24 \\
17 \\
12\end{array}$ \\
\hline
\end{tabular}

Quadro 2. Valores de densidade do solo, macro, micro e porosidade total, obtidos antes da instalação do experimento, para três profundidades do latossolo roxo de Dourados (MS)

\begin{tabular}{ccccc}
\hline \multirow{2}{*}{ Profundidade $\begin{array}{c}\text { Densidade } \\
\text { do solo }\end{array}$} & \multicolumn{3}{c}{ Porosidade } \\
\cline { 3 - 5 } & & Macro & Micro & Total \\
\hline $\mathrm{cm}$ & $\mathrm{kg} \mathrm{dm}^{-3}$ & & & $\mathrm{~m}^{3} \mathrm{~m}^{-3}$ \\
\hline $0-10$ & 1,2 & 0,22 & 0,37 & 0,59 \\
$10-20$ & 1,3 & 0,18 & 0,38 & 0,56 \\
$20-30$ & 1,3 & 0,15 & 0,40 & 0,55 \\
\hline
\end{tabular}

de Duncan, ao nível de 5\%. As perdas acumuladas de sol o e de água por erosão ea produtividade acumulada desoja edetrigo foram relacionadas com otempo (anos) decultivo, ajustando-se os dados a modelos matemáticos.

\section{RESULTADOS E DISCUSSÃO}

\section{Perdas de solo e água}

O sistema de preparo de sol o PD foi o tratamento mais eficiente no control e das perdas de solo e de água (Quadro 3). Na média geral, as perdas de solo nesse sistema foram de $787 \mathrm{~kg} \mathrm{ha}^{-1} \mathrm{ano}^{-1}$, ou seja, cerca de quatro, sete e nove vezes menores que as perdas no ES, GP e DE, respectivamente. As perdas de água no $\mathrm{PD}$ foram, em média, $27 \mathrm{~mm}_{\text {ano-1 ou, respectivamente, }}$ cerca de três, quatro e seis vezes menores que as no ES, GP e DE. O sistema GP apresentou perdas relativamente el evadas, se comparadas às do PD, ou mesmo do ES. Mesmo sem envolver rotação de culturas, o PD foi altamente eficaz no controle das perdas por erosão, principal mente porque a cobertura do sol o com pal ha atingiu $80 \%$, durantea mai or parte do ano e ao longo do período estudado. Isso, aliado a outros possíveis fatores concomitantes, como maior estabilidade da estrutura e agregação do solo, provavelmente elevou a infiltração eo armazenamento de água nesse sistema. A eficiência do PD no controle das perdas de água foi relativamente inferior à do controle das perdas de solo. I sso indica que não se deve recomendar a eliminação de terraços em áreas onde esse sistema é utilizado, sem considerar um adequado estudo técnico sobre, por exemplo, a rel evância das perdas na enxurrada de nutrientes em solução, visto que, a longo prazo, mesmo sob esse sistema, tais perdas podem gerar eutroficação de mananciais hídricos.

Os sistemas de preparo DE e GP, promovendo mai or exposição da superfície do sol o aos impactos das gotas de chuva eà formação de crostas, geraram mais erosão. Essa alta erosão, no caso do GP, deveu-se à compactação subsuperficial que limita a percolação da água. As perdas de solo no DE foram, em média, de 7,3 t ha-1 ano-1, índice rel ativamente mais el evado do que os verificados por Lombardi Neto et al. (1980) e por Castro et al. (1982, 1986), que trabal haram com um LR de 0,065 $\mathrm{m} \mathrm{m}^{-1}$ de declividade, em Campinas (SP). Segundo esse resultado, conjugado a outras observações de campo, a tol erância máxima de perdas desolo do LR em Dourados (MS) foi menor quea obtida por Lombardi Neto et al. (1980), em Campinas (SP). O controle das perdas de solo e de água, em relação ao DE, foi, respectivamente, de 61 e $46 \%$, para o ES; de 27 e $25 \%$, para o GP, e de 89 e $82 \%$, para o PD, ratificando a efetividade de PD eES, apresentada por outros autores, como Castro et al. (1982), que também relataram comportamento intermediário para a escarificação. Os níveis de controle aqui obtidos são semel hantes aos de Fabrício (1985), ratificam os de Hernani (1991) esão bastantepróximos dos deBiscaia (1978), que trabalhou com um latossolo vermel hoescuro.

As perdas anuais de solo acumuladas em função do tempo ajustaram-se a um modelo linear com coeficientes angulares positivos nos casos dos tratamentos DE, GP e ES (Figura 1). Para o PD, um modelo logarítmico ajustou-se mel hor aos dados, indicando que as perdas acumuladas de solo, nesse tratamento, tenderam, ao longo do período de duração do experimento, a estabilizar-se. No caso dos demais tratamentos e para o intervalo de tempo do 
Quadro 3. Perdas anuais de solo e de água por erosão de um latossolo roxo de Dourados (MS), em diferentes sistemas $^{(1)}$ de preparo de solo aplicados na sucessão soja/trigo, entre 1987 e 1994

\begin{tabular}{|c|c|c|c|c|c|c|c|c|}
\hline \multirow{3}{*}{ Período } & \multicolumn{8}{|c|}{ Sistemas de preparo do solo } \\
\hline & \multicolumn{2}{|c|}{ ES } & \multicolumn{2}{|c|}{ GP } & \multicolumn{2}{|c|}{ PD } & \multicolumn{2}{|c|}{ DE } \\
\hline & Solo & Água & Solo & Água & Solo & Água & Solo & Água \\
\hline & $\mathrm{kg} \mathrm{ha}^{-1}$ & $\mathrm{~mm}$ & $\mathrm{~kg} \mathrm{ha}^{-1}$ & $\mathrm{~mm}$ & $\mathrm{~kg} \mathrm{ha}^{-1}$ & $\mathrm{~mm}$ & $\mathrm{~kg} \mathrm{ha}^{-1}$ & $\mathrm{~mm}$ \\
\hline $1987 / 88$ & 2.672 & 124 & 6.242 & 148 & 1.878 & 69 & 9.317 & 168 \\
\hline $1988 / 89$ & 1.545 & 35 & 2.793 & 49 & 750 & 16 & 3.911 & 58 \\
\hline $1989 / 90$ & 4.526 & 121 & 7.684 & 160 & 571 & 14 & 8.302 & 203 \\
\hline 1990/91 & 1.631 & 54 & 2.186 & 61 & 90 & 6 & 7.833 & 165 \\
\hline $1991 / 92$ & 2.086 & 71 & 4.838 & 152 & 636 & 19 & 5.909 & 223 \\
\hline $1992 / 93$ & 2.195 & 89 & 5.023 & 111 & 1.038 & 50 & 8.268 & 125 \\
\hline $1993 / 94$ & 5.203 & 65 & 8.223 & 105 & 546 & 14 & 7.288 & 104 \\
\hline Média & 2.837 & 80 & 5.284 & 112 & 787 & 27 & 7.261 & 149 \\
\hline (\%) Relativa ${ }^{(2)}$ & 39 & 54 & 73 & 75 & 11 & 18 & 100 & 100 \\
\hline (\%) Controle $e^{(3)}$ & 61 & 46 & 27 & 25 & 89 & 82 & - & - \\
\hline
\end{tabular}

${ }^{(1)}$ ES: escarificação + gradagem niveladora, GP: gradagens pesada + niveladora, PD: plantio direto, DE : sistema convencional, sem cobertura vegetal. ${ }^{(2)}(\%)$ Relativa:perdas relativas ao tratamento DE, considerado como $100 .{ }^{(3)}(\%)$ Controle: em relação ao tratamento DE.

experimento, as perdas acumuladas cresceram, em média, 7,2; 5,0 e 2,6 t ha-1 ano-1, respectivamente, para DE , GP e ES. Quanto às perdas acumuladas de água em função do tempo, observou-se tendência linear para todos os tratamentos, sendo os coeficientes angulares, aqui transformados de dm ano-1 para $\mathrm{mm}^{2} \mathrm{no}^{-1}$, de 159; 110; 75 e 20 mm ano-1, respectivamente, para DE, GP, ES e PD. Nesse caso, todos os coeficientes angulares foram positivos, até mesmo para o PD, cujas perdas acumuladas de água tenderam a crescer, em média, 20 mm ano-1. I sso indica que, no PD, o controle das perdas de água foi, relativamente, menos eficiente do que o controle das perdas de solo, fato provavelmente relacionado com a menor rugosidade desse tratamento e com o tipo de resíduos (soja e trigo) que constituíram a cobertura morta. Os resultados demonstraram que, em PD, o solo foi submetido a perdas de solo e água menos intensas e em taxas menores, caracterizando-o como o mais sustentável dos sistemas para o cultivo da sucessão soja/trigo na região.

O número de chuvas erosivas por ano, entre 1987 e 1994, variou de 14 a 37. A relação entrea pluviosidade anual e o número anual de chuvas erosivas foi do tipo exponencial, expressa por: $y=8,685 \mathrm{e}^{0,001 x}$; em que y $=$ número anual de chuvas erosivas ex $=$ precipitação acumulada anual (mm). A tendência de aumento da quantidade de chuvas erosivas com a pluviosidade indica que os cuidados com a cobertura e proteção do sol o, nessa região, devem ser redobrados, especial mente entre os meses de novembro e março.

As perdas acumuladas de sol o dos tratamentos GP e DE, referentes ao período abril/1994 a abril/95, respectivamente, de 10,3 e 11,8 t ha-1 $^{-1}$ ano-1, foram mais elevadas, e as de ES e PD, respectivamente, de 2,0 e
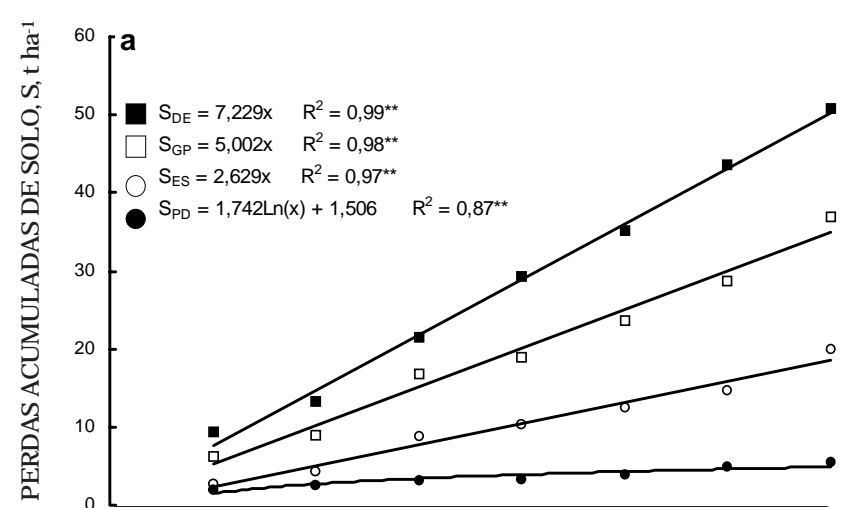

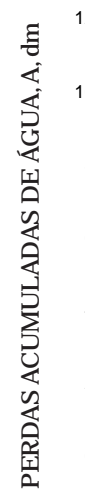

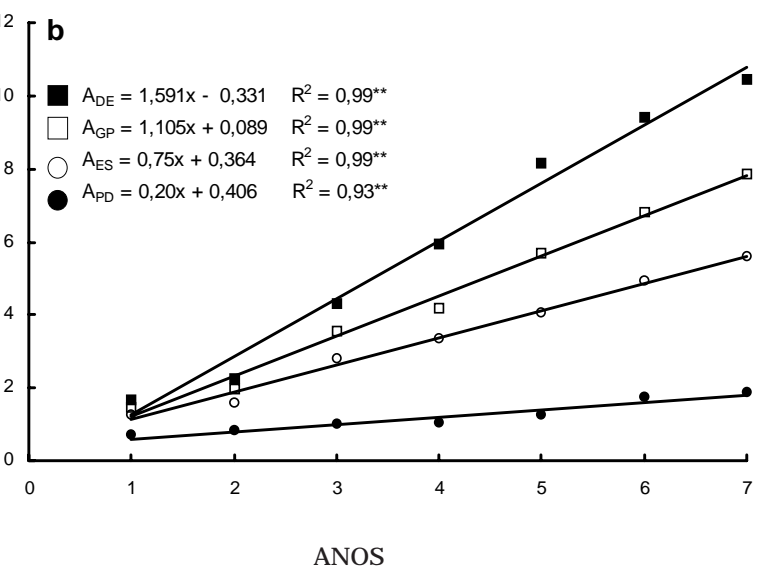

Figura 1. Perdas acumuladas de solo (a) e de água (b), em função do tempo (anos), para os sistemas de preparo: escarificação +gradagem niveladora (ES); gradagens pesada + niveladora (GP); plantio direto (PD) e aração + duas gradagens niveladoras, sem cobertura vegetal (DE). 
0,3 t ha-1, foram menos elevadas, do que a média desses sistemas para o período 1987-1994, ou seja, 5,3; 7,3; 2,8 e 0,8 t ha-1 $^{-1}$ ano-1, $^{-1}$ respectivamente, para GP, DE, ES ePD (Quadro 4). As perdas mais el evadas verificadas nos sistemas de preparo GP e DE refletiram número relativamente el evado de chuvas erosivas, 28, ocorridas nesse período e, no caso do GP, refletiram os baixos níveis de cobertura do solo ocorridos, no ano agrícola 1994/95, em ambas as culturas. Comparados ao DE, os tratamentos PD, ES e GP, nesse período, controlaram, respectivamente, $98 \%, 83 \%$ e $13 \%$ das perdas de solo, ratificando a elevada eficiência dos dois primeiros em relação ao GP, quanto a esse aspecto. As perdas totais de água para o período 1994/95 foram de 47; 147; 11 e $154 \mathrm{~mm}$ ano $^{-1}$, respectivamente; para ES, GP, PD e $\mathrm{DE}$, enquanto as perdas médias para o período 19871994, foram de 80; 112; 27 e 149 mm ano-1, respectivamente, para ES, GP, PD e DE. O comportamento dos tratamentos, nesse caso, é semelhanteao discutido anteriormente para as perdas de solo. $\mathrm{O}$ índice de controle de perdas de água, em relação ao $\mathrm{DE}$, foi de $93 \%$, para oPD; $69 \%$, para oES, e 4\%, para o GP. Entre a semeadura do trigo/94 e o $30^{\circ}$ dia (T1), não houve ocorrência de chuvas, o que gerou baixoíndice de cobertura de sol o, especial mente no GP, visto que a ausência de umidade afetou o estande geral da cultura.

O período S1 durou dois dias e apresentou, em termos relativos, a maior perda de solo por unidade de tempo, em todos os tratamentos. Isso pode estar associado aos índices de erosividade mais elevados, coincidentes à maior exposição do solo à chuva, especialmente no GP eDE (Quadro4). Por outrolado, tal período expressa os efeitos dos sistemas de preparo imediatamente após sua execução, em parâmetros como o controle de erosão ea infiltração, os quais foram mais el evados nos sistemas PD eES do que naqueles que geraram mai ores perturbação e exposi ção do sol o (GP eDE). As maiores per das absol utas de sol o foram observadas em T2, S4, S3 e S3, respectivamente, para ES, GP, PD e DE; as de água foram sempre mais el evadas em S3. I sso refletea duração e pl uviosidades mais el evadas dos períodos S3 e S4, em relação aos demais. As perdas de solo durante o cultivo da soja, no tratamento GP, foram três vezes superiores às verificadas durante o cultivo do trigo, em razão da menor ocorrência de chuvas erosivas durante o cultivo da gramínea. Por outro lado, no DE, essas perdas for am cinco vezes superiores às do GP, indicando que a proteção realizada pel as culturas explica, em grande parte, as diferenças entre esses tratamentos. Dedecek et al. (1986) relataram comportamento eficiente da soja em relação a outras culturas, e Eltz et al. (1977) salientaram a eficiência da soja em comparação ao trigo. Nos períodos iniciais da cultura da soja, $\mathrm{Sl}$ e S2, não foram observadas diferenças entre os tratamentos em relação à infiltração; o que, entretanto, não ocorreu, nos períodos seguintes, S3, S4 eF 2, para os tratamentos DE ePD. I sso demonstra a grandeinfluência da cobertura, seja devida à palha, seja à proporcionada pelo dossel da cultura, na infiltração e, conseqüentemente, no controle da erosão, ratificando resultados de Dedecek et al. (1986).

Quadro 4. Pluviosidade, perdas de solo e de água e infiltração em diferentes sistemas de preparo de solo e períodos de cultivo da sucessão trigo/soja, ano agrícola 1994/95, num latossolo roxo muito argiloso de Dourados (MS)

\begin{tabular}{|c|c|c|c|c|c|c|c|c|c|c|c|c|c|}
\hline \multirow{3}{*}{ Período $^{(2)}$} & \multirow{3}{*}{ Chuva } & \multicolumn{12}{|c|}{ Sistema de preparo ${ }^{(1)}$} \\
\hline & & \multicolumn{3}{|c|}{ ES } & \multicolumn{3}{|c|}{$\mathbf{G P}$} & \multicolumn{3}{|c|}{ PD } & \multicolumn{3}{|c|}{ DE } \\
\hline & & Solo & Água & Infiltração & Solo & Água & Infiltração & Solo & Água & Infiltração & Solo & Água & Infiltração \\
\hline & $\mathrm{mm}$ & $\mathrm{t} \mathrm{ha}^{-1}$ & $\mathrm{~mm}$ & $\%$ & $\mathrm{t} \mathrm{ha}^{-1}$ & $\mathrm{~mm}$ & $\%$ & $\mathrm{t} \mathrm{ha}^{-1}$ & $\mathrm{~mm}$ & $\%$ & $\mathrm{t} \mathrm{ha}^{-1}$ & $\mathrm{~mm}$ & $\%$ \\
\hline $\mathrm{T} 1$ & 0 & 0 & 0 & 0 & 0 & 0 & 0 & 0 & 0 & 0 & 0 & 0 & 0 \\
\hline T 2 & 155 & 0,80 & 11 & 93 & 0,79 & 15 & 90 & 0,00 & 1 & 99 & 0,33 & 8 & 95 \\
\hline T 3 & 122 & 0,42 & 5 & 96 & 1,70 & 28 & 77 & 0,01 & 1 & 99 & 1,06 & 17 & 86 \\
\hline F 1 & 200 & 0,03 & 3 & 98 & 0,19 & 6 & 97 & 0,01 & 1 & 100 & 0,86 & 18 & 91 \\
\hline S 1 & 56 & 0,22 & 3 & 95 & 0,58 & 6 & 89 & 0,08 & 1 & 98 & 0,39 & 5 & 91 \\
\hline S 2 & 42 & 0,01 & 1 & 98 & 0,10 & 1 & 98 & 0,03 & 1 & 98 & 0,19 & 2 & 95 \\
\hline S 3 & 246 & 0,39 & 19 & 92 & 0,72 & 45 & 82 & 0,09 & 3 & 99 & 4,24 & 58 & 76 \\
\hline F 2 & 125 & 0,02 & 2 & 98 & 0,03 & 2 & 98 & 0,03 & 1 & 99 & 2,45 & 27 & 78 \\
\hline Total & 1054 & 1,95 & 47 & - & 10,28 & 147 & - & 0,26 & 11 & - & 11,76 & 154 & - \\
\hline
\end{tabular}

(1)ES: escarificação + gradagem niveladora; GP: gradagens pesada + niveladora; PD: plantio direto; DE: sistema convencional, sem cobertura vegetal. ${ }^{(2)}$ T 1: da semeadura do trigo ao $30^{\circ}$ dia após; T2: do $30^{\circ}$ ao $60^{\circ}$ dia após a semeadura; T3: do $60^{\circ}$ dia à col heita do trigo; F 1: da col heita do trigo até o preparo de solo para a soja; S1: do preparo de solo até a semeadura da soja; S2: da semeadura ao 30 dia após; S3: do $30^{\circ}$ ao $60^{\circ}$ dia após a semeadura; S4: do $60^{\circ}$ dia à colheita da soja; F 2: da col heita da soja até o preparo de sol o/semeadura do trigo subsequente. 


\section{Fator erosividade (R)}

O fator erosividade (R) para Dourados (MS) e para o período de vinteetrês anos (1972-1994), determinado com base em Lombardi Neto \& Moldenhauer (1980), foi de $6.411 \mathrm{MJ} \mathrm{mm} \mathrm{ha-1}^{-1} \mathrm{~h}^{-1}$ ano $^{-1}$. Mato Grosso do Sul (1992) reportou R de $612 \mathrm{tm} \mathrm{mm/ha.h.ano} \mathrm{(cerca} \mathrm{de}$

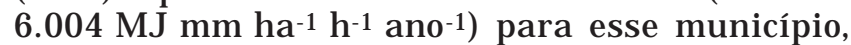
baseado em pluviosidade do período 1976-1985, e Vitorino \& Rosa Júnior (1994) relataram 7.201 MJ mm ha-1 $\mathrm{h}^{-1}$ ano-1, para o período 1980-1990. Tais resultados são relativamente divergentes dos obtidos neste trabal ho, possivel mente por terem sido os períodos utilizados por esses autores de novee onze anos, respectivamente, menores que os 22 anos recomendados por Lombardi Neto \& Moldenhauer (1980). Tais resultados, entretanto, concordam com os obtidos por Rufino et al. (1993) que apresentaram valores entre 6.000 e 7.000 para a região noroeste do Paraná, próxima à fronteira de Mato Grosso do Sul e São Paulo. Carval ho et al. (1989) identificaram efeito positivo do período de retorno no val or da erosividade, para a região de Mococa (SP). A regressãolinear entre - El e a precipitação média mensal, r, para esse período, resultou: $\mathrm{El}=4,4604$. r, sendo o coeficiente de determinação $R^{2}=0,897$. Assim, em cerca de $90 \%$ dos casos, a erosividade das chuvas deveu-se à pluviosidade média mensal, realçando a importância dos meses mais chuvosos na erosividade e na ocorrência da erosão, o que indica a possibilidade do uso dessa equação para estimar a erosividade.

\section{Fator erodibilidade (K)}

$\mathrm{N}$ a determinação do $\mathrm{K}$, utilizou-se $a$ fórmula: $\mathrm{K}=$ A/R.LS.C.P, em que A é o val or médio das perdas de solo $(=7,261$ t ha-1 ano-1) determinado com o tratamento $\mathrm{DE} ; \mathrm{R}$, fator erosividade = $6.411 \mathrm{MJ} \mathrm{mm} \mathrm{ha-1}^{-1} \mathrm{ano}^{-1} ; \mathrm{S}$, fator grau do declive $=$ 0,26 e L, fator comprimento do declive; $C$, fator uso e manejo do solo, e P, fator práticas conservacionistas, os quais, no caso da parcela-padrão, são iguais a 1. Portanto, oK resultou em 0,0045 t h MJ -1 $\mathrm{mm}^{-1}$, val or relativamente menor que os reportados por outros autores, como Carval ho et al. (1993), que estimaram o fator erodibilidade para o LR de Campinas (SP) em $0,0101 \mathrm{t} \mathrm{h} \mathrm{MJ}{ }^{-1} \mathrm{~mm}^{-1}$, mas concordam com os observados por Denardin (1990), que analisou nove latossolos, reportando val ores de erodibilidade entre 0,002 e 0,034 t h MJ -1 $\mathrm{mm}^{-1}$. O fator erodibilidade (K), aqui obtido, ratificou a al ta tolerância à erosão do solo em estudo. Isto deve-se à el evada infiltração e drenagem interna desse solo, que, como salientaram Silva et al. (1994), éconseqüência de sua mineral ogia sesquioxídica, que confere aos latossolos forte desenvolvimento de microestrutura granular e elevada permeabilidade.

\section{Rendimentos de grãos de soja e de trigo}

A produtividadeao longo do temposofreu variações decorrentes de eventos climáticos, como estiagens prolongadas, principalmente no período inicial de desenvolvimento da soja, em 1989/90 e 1993/94, e do trigo, em 1989, 1992 e 1994 (Quadro 5). No caso da soja, tais estiagens (veranicos) também ocorreram durante o mês de janeiro, na maioria dos anos estudados; geadas moderada e forte também influenciaram o rendimento do trigo em quase todos os anos, especialmente nos supracitados. O PD apresentou, ao longo do tempo, maior estabilidade na produção e rendimentos médios de grãos superiores aos demais sistemas, tanto em soja como em trigo.

A quantidade média de pal ha, avaliada ao final da cultura do trigo, foi de 5,4; 4,1 e 3,3 t ha-1, para PD, ES e GP, respectivamente. Esse diferencial no montante de cobertura ea ausência de revolvimento do solo determinaram, provavelmente, maiores proteção do solo, disponibilidade de água, conforme relataram Sidiras et al. (1983), e de nutrientes, refletindo-se na produtividade da soja subseqüente. Assim, quanto aos rendimentos de grãos de soja, o PD foi $17 \%$ superior ao GP, na média geral, e $25 \%$ mais produtivo na média dos últimos cinco anos. $\mathrm{O}$ ES apresentou efeitos intermediários entre o PD e o GP, sendo, na média do período, $5 \%$ superior a este último. A queda no rendimento de grãos observada no ano agrí́cola 1993/94, tanto no ES como no GP, deveu-se à seca prolongada, ocorrida após a germinação da soja, a qual proporcionou severo ataque de broca do colo (E. lignosel us), afetando o estande, especialmente no ES. A quantidade média de pal ha no período da col heita da soja foi de 6,4 t ha-1, no PD, e 5,1 t ha-1, no ES, respectivamente, $39 \%$ e $12 \%$ superiores ao verificado no GP. Considera-se que esse montante de pal ha era o que existia no momento da semeadura do trigo, visto ser, na região, o período entre a col heita de soja e a semeadura subseqüente do trigo relativamente pequeno. Assim, os efeitos dessa palha, principalmente na conservação da água, refletiramse nos rendimentos de grãos de trigo. Em conseqüência, o PD, na média geral, foi $17 \%$ superior e, nos últimos quatro anos (90 a 93, inclusive), $20 \%$ mais produtivo que o GP, indicando, também, que os efeitos do sistema mais conservacionista expressaramse mais intensamente com o decorrer do tempo. O ES apresentou rendimentos de trigo semel hantes aos do PD esignificativamente superiores aos do GP, em 12\% em termos de média geral.

Rendimentos relativos ao GP acumulados em função do tempo de cultivo, dos sistemas PD e ES, demonstraram incrementos dos rendimentos relativos ao longo do tempo (Figuras 2 e 3). No caso da soja, o PD apresentou comportamento linear, e o ES, tendência logarítmica de evolução desse parâmetro (F igura 2); notrigo, a tendência foi do tipo logarítmico (Figura 3). Distanciando-se cada vez mais do GP, o PD apresentou rendimentos relativos acumulados sempre crescentes ao longo do tempo, para ambas as culturas, tendo o sistema apresentado maior rendimento relativo acumulado. O ES apresentou comportamento intermediário entre o PD e o GP. J aster at al. (1993), em estudos realizados em Guarapuava (PR), também demonstraram que a semeadura direta contínua foi, quanto aos rendimentos de grãos, o mais efetivo dos sistemas de preparo para a sucessão soja/trigo. 
Quadro 5. Rendimentos de grãos de soja e de trigo, cultivados em sucessão, relativos aos sistemas(1) de preparo de solo e ao período 1987-1994

\section{Sistema de preparo}

\begin{tabular}{|c|c|c|c|c|c|c|}
\hline \multirow[t]{2}{*}{ Período } & \multicolumn{3}{|c|}{ Rendimento de grão de soja } & \multicolumn{3}{|c|}{ Rendimento de grão de trigo } \\
\hline & ES & GP & PD & ES & GP & PD \\
\hline & \multicolumn{6}{|c|}{ - kgha ${ }^{-1}$} \\
\hline 1987/88 & 3.340 & 3.540 & 3.570 & 1.860 & 1.880 & 1.940 \\
\hline $1988 / 89$ & 2.290 & 2.210 & 2.520 & $r d^{(2)}$ & rd & rd \\
\hline 1989/90 & 1.859 & 1.382 & 1.532 & 2.329 & 2.012 & 2.400 \\
\hline 1990/91 & 1.933 & 1.867 & 2.011 & 2.768 & 2.427 & 2.956 \\
\hline 1991/92 & 1.826 & 1.552 & 2.259 & 1.529 & 1.363 & 1.388 \\
\hline 1992/93 & 2.507 & 2.257 & 2.883 & 2.643 & 2.233 & 2.910 \\
\hline 1993/94 & 1.113 & 1.403 & 1.887 & rd & rd & rd \\
\hline Média ${ }^{(3)}$ & $2.124 \mathrm{~b}(105)$ & $2.030 \mathrm{~b}(100)$ & $2.380 \mathrm{a}(117)$ & 2.225 a (112) & 1.983 b (100) & 2.319 a (117) \\
\hline CV\% & \multicolumn{3}{|c|}{9,5} & \multicolumn{3}{|c|}{6,9} \\
\hline$F^{(4)}$ & \multicolumn{3}{|c|}{$*$} & \multicolumn{3}{|c|}{$*$} \\
\hline
\end{tabular}

${ }^{(1)}$ ES: escarificação + gradagem niveladora, GP: gradagens pesada + niveladora, PD: plantio direto. ${ }^{(2)}$ rd: rendimentos muito baixos, foram desconsiderados para efeito de análise estatística. ${ }^{(3)}$ Dentro de cultura, médias seguidas de mesma letra, na linha, não diferem entre si (Duncan, 5\%); valores entre parênteses são relativos ao do GP; para a cultura do trigo a média foi relativa a cinco anos. ${ }^{(4)}$ Teste $\mathrm{F}, *=$ significativo ao nível de $5 \%$.

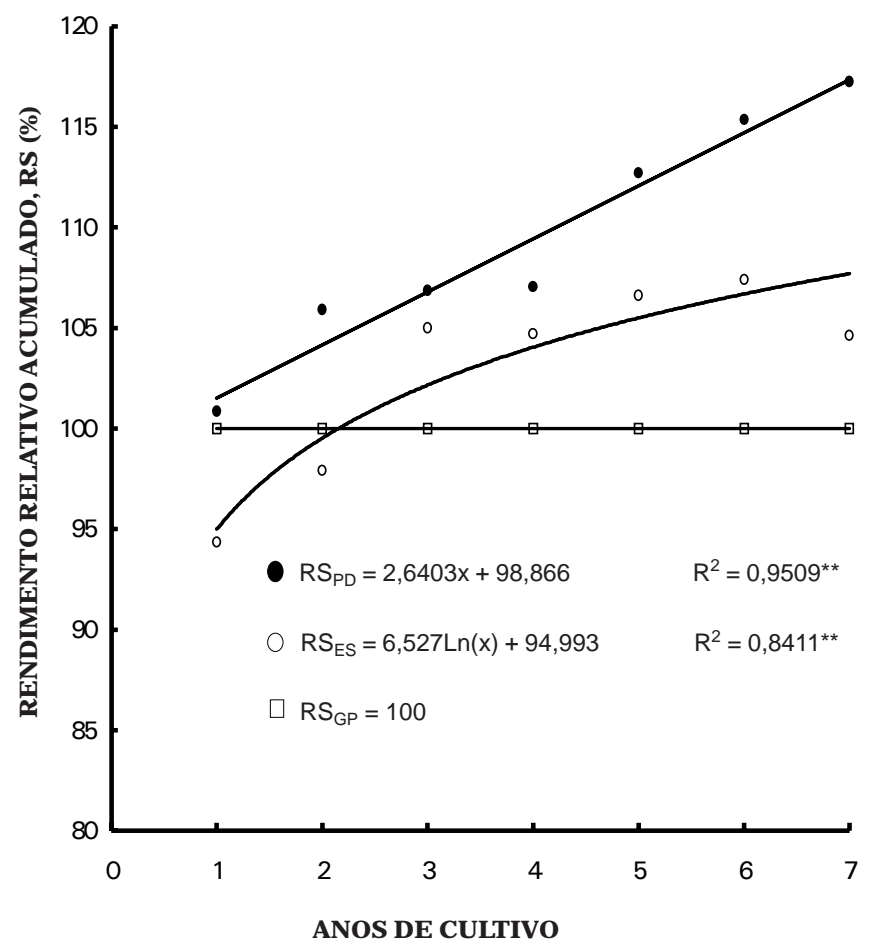

Figura 2. Rendimentos relativos acumulados de grãos de soja (RS) em plantio direto (PD) e com escarificação + gradagem niveladora (ES), considerando os sistemas de preparo com gradagens pesada + niveladora (GP), em função do tempo de cultivo.

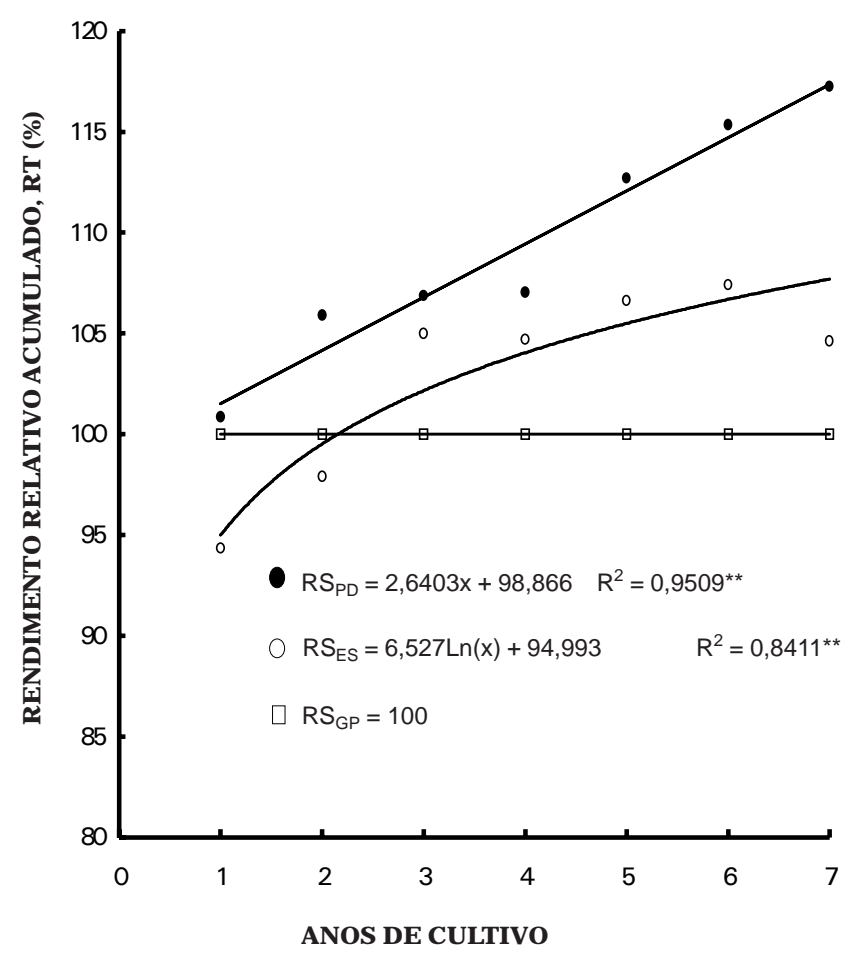

Figura 3. Rendimentos relativos acumulados de grãos de trigo (RT) em plantio direto (PD) e com escarificação + gradagem niveladora (ES), considerando os sistemas de preparo com gradagens pesada + niveladora (GP), em função do tempo de cultivo. 


\section{CONCLUSÕES}

1. O plantio direto foi o sistema mais eficaz no controle das perdas de sol o e água por erosão e o que proporcionou os maiores rendimentos de grãos de soja e de trigo, cultivados em sucessão. O sistema de gradagens pesada + niveladora foi o menos eficaz e o escarificação + gradagem niveladora apresentou comportamento intermediário.

2. As perdas acumuladas de solo, no intervalo de tempo experimental, no plantio direto tenderam a se estabilizar, enquanto, nos sistemas convencional, descoberto; gradagens pesada + niveladora e escarificação + gradagem niveladora, cresceram, em média, 7,2; 5,0 e 2,6 t ha-1 ano-1, respectivamente. As perdas acumuladas de água, em relação ao tempo, seguiram um model olinear com coeficientes angulares positivos para todos os sistemas de preparo de solo estudados.

3. O período crítico em termos de perdas de solo e água ocorreu entre o preparo de solo e a semeadura da soja, exigindo maiores cuidados com a cobertura e proteção do sol o entre os meses de novembro e março.

4. O fator erosividade, R, para Dourados (MS), foi de $6.411 \mathrm{MJ} \mathrm{mm} \mathrm{ha}^{-1} \mathrm{ano}^{-1}$, e ofator erodibilidade, $\mathrm{K}$, para o latossolo roxo muito argiloso, foi de $0,0045 \mathrm{t} \mathrm{h}$ MJ $-1 \mathrm{~mm}^{-1}$.

\section{LITERATURA CITADA}

BERTONI, J. \& LOMBARDI NETO, F. Conservação do solo. Piracicaba, Livroceres, 1985. 392p.

BISCAIA, R.C.M. Perdas de solo em diferentes tipos de preparo para a sucessão trigo-soja, sob chuvas naturais. In: ENCONTRO NACIONAL DE PESQUISA SOBRE CONSERVAÇÃO DO SOLO, 2., Passo Fundo, 1978. Anais. Passo Fundo, EMBRAPA/CNPT. 1978. p.247-256.

CARVALHO, M.P.; CATANEO,A.\& LOMBARDI NETO, F. Índices de erosividade da chuva e enxurrada correlacionados com as perdas de sol o e determinação de erodi bilidade de um latossolo roxo distrófico de Campinas (SP). R. bras. Ci. Solo, Campinas, 17:445-450, 1993.

CARVALHO, M.P.; LOMBARDI NETO, F.; VASQUES FILHO, J. \& CATANEO, A. Erosividade da chuva de Mococa, SP, analisada pel oíndice $\mathrm{EI}_{30}$. R. bras. Ci. Solo, Campinas, 13:243249, 1989.

CASTRO, O.M. de; LOMBARDI NETO, F. \& DECHEN, S.C.F. Sistemas de preparo de solo para a cultura do milho e as perdas por erosão. In: ENCONTRO NACIONAL DE PESQUISA SOBRE CONSERVAÇÃO DO SOLO, 4., Campinas, 1982. Resumos. Campinas, Sociedade Brasileira de Ciência do Solo,1982. p.23.

CASTRO, O.M. de; LOMBARDI NETO, F.; VIEIRA, S.R. \& DECHEN, S.C.F. Sistemas convencionais e reduzidos de preparo do solo e as perdas por erosão. R. bras. Ci. Solo, Campinas, 10:167-72, 1986.
COGO, N.P. U ma contribuição à metodol ogia de estudo das perdas por erosão em condições de chuva natural: I - Sugestões gerais, medição do volume, amostragem e quantificação de solo e água da enxurrada. In: ENCONTRO NACIONAL DE PESQUISA SOBRE CONSERVAÇÃO DO SOLO, 2., PaSSO Fundo, 1978. Anais. Passo Fundo, EMBRAPA-CNPT, 1978. p.75-97.

DEDECEK, R.A. \& CABEDA, M.S.V. Fator de erodibilidade de oxissol os no Rio Grande do Sul. Pesq. agropec. bras., Brasília, 12:91-96, 1977.

DEDECEK, R.A.; RESCK, D.V.S. \& FREITAS J ÚNIOR., E. Perdas de solo, água e nutrientes por erosão em latossolo vermel hoescuro dos cerrados em diferentes cultivos sob chuva natural. R. bras. Ci. Solo, Campinas, 10:265-272, 1986.

DENARDIN, J.R. Erodibilidade do solo estimada por meio de parâmetros físicos e químicos. Piracicaba, ESALQ, 1990. 106p. (Tese de Doutorado)

ELTZ, F.L.F.; COGO, N.P. \& MIELNICZUK, J. Perdas por erosão em diferentes manejos de solo e coberturas vegetais em solo laterítico bruno avermelhado distrófico (São Gerônimo). I. Resultados do primeiro ano. R. bras. Ci. Solo, Campinas, 1:123-127, 1977.

EMPRESA BRASILEIRA DE PESQUISA AGROPECUÁRIA (EMBRAPA). Unidade de Execução de Pesquisa de Âmbito Estadual de Dourados. Soja: recomendações técnicas para Mato Grosso do Sul. Dourados, EMBRAPA-UEPAE Dourados, 1992. 179p. (Circular Técnica, 22)

EMPRESA BRASILEIRA DE PESQUISA AGROPECUÁRIA (EMBRAPA). Unidade de Execução de Pesquisa de Âmbito Estadual de Dourados (UEPAE Dourados). Trigo: recomendações técnicas para Mato Grosso do Sul. Dourados, EMBRAPA-UEPAE Dourados, 1991. 154p. (Circular Técnica, 19)

FABRíCIO, A.C. Estudo da erosividade das chuvas e erodibilidade dos solos no Mato Grosso do Sul. Dourados, EMBRAPAUEPAE, 1985. 6p. (Projeto 043800085, Form. 13/85)

HERNANI, L.C. Sistemas de manejo e perdas por erosão de um latossolo roxo distrófico argiloso, sob chuva natural. In: REUNIÃO DA COMISSÃO CENTRO-SUL-BRASILEIRA DE PESQUISA DE TRIGO, 7., Curitiba, 1991. Resultados de pesquisa com trigo - 1990. Dourados, EMBRAPA-UEPAE, 1991. (Documentos, 47)

JASTER, F.; ELTZ, F.F.L.; FERNANDES, F.F.; MERTEN, G.H.; GAUDÊNCIO, C. de A. \& OLIVEIRA, M.C.N. de. Rendimento de grãos em diferentes sistemas de preparo e manejo de solos. Londrina, EMBRAPA-CNPSo, 1993. 37p. (Documentos, 61)

LOMBARDI NETO, F. \& BERTONI, J. Tolerância de perdas de terra para solos do Estado de São Paulo. Campinas, IAC, 1975. 12p. (Boletim Técnico, 28)

LOMBARDI NETO, F.; CASTRO, O.M. de; DECHEN, S.C.F.; SI LVA, I.R. da \& BE NATTI J Ú NIOR, R. Sistemas de preparo do solo em relação à erosão e à produção. In: CONGRESSO BRASILEIRO DE CONSERVAÇÃO DO SOLO, 3., Brasília, 1980. Resumos. Brasília, Ministério da Agricultura/SBCS, 1980. p.26.

LOMBARDI NETO, F. \& MOLDENHAUER, W.C. Erosividade da chuva: sua distribuição e relação com perdas de solo em Campinas (SP). In: ENCONTRO NACIONAL DE PESQUISA SOBRE CONSERVAÇÃO DO SOLO, 3., Recife, 1980. Anais. Recife, UFRP, 1980. p.158. 
MATO GROSSO DO SUL. Secretaria de Planejamento e Coordenação Geral. Atlas multirreferencial. Campo Grande: 1990. 28p.

MATO GROSSO DO SUL. Secretaria de Estado de Planejamento e de Ciência e Tecnologia. Susceptibilidade à erosão da Macrorregião da Bacia do Paraná. Campo Grande, 1992. 227p.

RUFINO, R.L.; BISCAIA, R.C.M. \& MERTEN, G.H. Determinação do potencial erosivo da chuva do Estado do Paraná, através de pluviometria: terceira aproximação. R. bras. Ci. Solo, Campinas, 17:439-444, 1993.

SIDIRAS, N.; DERPSCH, R. \& MONDARDO, A. Influência de diferentes sistemas de preparo do sol ona variação da umidade e rendimento da soja em Latossolo Roxo distrófico (Oxissol). R. bras. Ci. Solo, Campinas, 7:103-106, 1983.

SILVA, C.M. da; BARBO, C.V.S.; GOMEZ, S.A.; SONEGO, O.R. \& MELHORANÇA, A.L. Recomendações técnicas para o cultivo da soja na região da Grande Dourados, 1986/1987. Dourados, EMBRAPA-UEPAE, 1986. 78p. (Circular Técnica, 13)
SILVA, M.LN.; CURI, N.; OLIVEIRA, M.S.; FERREIRA, M.M. \& LOMBARDI NETO, F. Comparação entre métodos direto e indiretos para a determinação da erodibilidade em latossolos sob cerrado. Pesq. agropec. bras., Brasília, 29:1751-1761, 1994.

SOUSA, P.G. Trigo: recomendações técnicas para Mato Grosso do Sul - safra 1987. Dourados, EMBRAPA-UEPAE Dourados, 1987. 72p. (Circular Técnica, 15)

VITORINO, A.C.T. \& ROSA J ÚNIOR, E.J. Erosividade da chuva em Dourados (MS). R. Científica, Campo Grande, 1:31-34, 1994.

WISCHMEIER, W.H. \& SMITH, D.D. Predicting rainfall erosion losses - a guide to conservation planning. Washington, USDA, 1978. (Agriculture Handbook, 537)

WUNSCHE, W.A. \& DENARDIN, J.E. Erodibilidade de latossolo vermel ho-escuroálico (unidade de mapeamento Passo F undo) - 1a. aproximação. In: ENCONTRO NACIONAL DE PESQUISA SOBRE CONSERVAÇÃO DO SOLO, 2., PasSo Fundo, 1978. Anais. Passo Fundo, EMBRAPA-CNPT, 1978. p.209-214. 